\title{
My last words on taper equations
}

\author{
by Antal Kozak ${ }^{1}$
}

\begin{abstract}
A brief review of the nearly half century of research related to taper equations in the Faculty of Forestry at the University of British Columbia is presented. Two new variable-exponent taper models, the 2001 and 2002 models, are introduced and compared to Kozak's 1988 and 1994 models. This comparison, based on 38 species groups consisting of 53603 trees, demonstrated that the 2002 model is consistently the best overall model of the four, and the 2001 model is the simplest in form and the best for estimating merchantable height. The results of this study also indicate that several fit statistics and lack-of-fit statistics should be used to create indices for ranking taper models for practical applications, instead of only a few.
\end{abstract}

Key words: taper, variable-exponent, history of taper models, comparison of taper models, evaluations of taper models

Cet article présente une revue sommaire de la recherche effectuée au cours de près d'un demi-siècle sur les équations de défilement à la Faculté de Foresterie de l'Université de Colombie-Britannique. Deux nouveaux modèles de défilement à exposants variables, les modèles 2001 et 2002, sont présentés et comparés aux modèles de 1988 et de 1994 de Kozak. Cette comparaison, reposant sur des groupes de 38 espèces comportant 53603 arbres, a indiqué que le modèle 2002 est constamment le meilleur modèle du groupe et que le modèle 2001 est le plus simple pour exprimer la forme et le meilleur pour estimer la hauteur marchande. Les résultats de cette étude indiquent également que plusieurs statistiques d'ajustement et d'absence d'ajustement devraient être utilisées pour créer des indices de classification des modèles de défilement dans le cas d'applications pratiques, au lieu de quelques-unes.

Mots-clés: défilement, exposant variable, historique des modèles de défilement, comparaison des modèles de défilement, évaluation des modèles de défilement

\section{Introduction}

Unlike volume equations, which only estimate total or merchantable stem volume, taper equations provide estimates of: (i) inside bark diameter at any point along the stem; (ii) total stem volume; (iii) merchantable volume and merchantable height to any top diameter and from any stump height; and (iv) individual log volumes of any length at any height from ground. To date, the Faculty of Forestry at the University of British Columbia (UBC) has spent close to a half century researching this topic. Since I was actively involved in this research for 38 of the 47 years, I decided to reflect on this rather exciting field of study to mark the end of my career. The objectives of this paper therefore are:

- to briefly review the history of taper equation research at UBC;

- to introduce and describe two new variable-exponent taper models; and

- to extend on the procedures of comparing and evaluating various taper estimating systems.

\section{The History of Taper Research at UBC}

In 1956, the demand for better volume estimating systems led Dr. J. Harry G. Smith and one of his graduate students, R. Monty Newnham, to start working on taper equations in the Faculty of Forestry at UBC. This research resulted in a Master's thesis by Newnham (1958). In the early 1960s, Dr. Don D. Munro and Dr. Smith continued this research and they invited me to collaborate when I joined the Faculty in 1965. I was honoured by their invitation. As I learned more about the topic, I became more and more fascinated by the challenges presented. What I did not realize at the time was that this research topic would become a lifetime passion.

Shortly after I joined the Faculty, we published a critical analysis of multivariate methods used in Sweden at the time

${ }^{1}$ Professor Emeritus, Department of Forest Resources Management, Faculty of Forestry, The University of British Columbia, 2045-2424 Main Mall, Vancouver, B.C. V6T 1Z4. E-mail: tony.kozak@ubc.ca
(Fries and Marten 1965) for estimating tree taper (Kozak and Smith 1966). This was followed by the publication of our first very simple, yet effective, taper equation (Kozak et al. 1969). Although this taper function produced somewhat biased estimates of inside bark diameter at several places along the stem (Fig. 1), it found its way into most of the forest inventory computer programs in B.C., Alberta, and several European

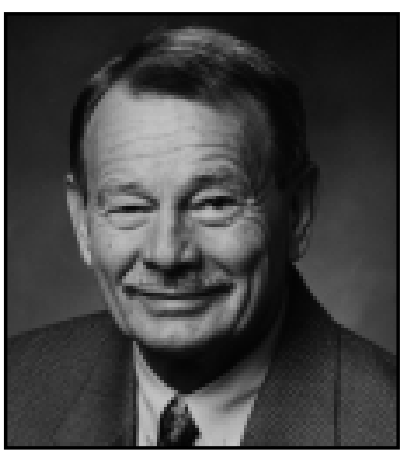

Antal Kozak countries, largely because of its simplicity.

In the following few years, Julian P. Demaerschalk worked on the compatibility of several volume equations and some taper estimating systems for his Master's and Ph.D. theses under the direction of Dr. Smith and myself (Demaerschalk 1971, 1973). Upon graduation in 1973, Dr. Demaerschalk joined the Faculty of Forestry, and also joined our small team of taper researchers. In an attempt to reduce the bias inherent in our 1969 taper equation, he and I developed the "whole-bole system." In this stem profile estimating system, two functions are linked together at the lower inflection point of the stem (between 10 and $30 \%$ of the total height from the ground, depending on the species) such that their derivatives are equal at the point of intersection (Demaerschalk and Kozak 1977). Although not all of the bias was eliminated with this system, the prediction was almost perfect along most parts of the stem (Fig. 1). The B.C. Ministry of Forests and several private companies immediately adopted this estimating system in B.C. for practical applications. The main difficulty with this estimating system, however, was that the equations were extremely difficult to fit. In the early 1980s Catherine A. James, another of my graduate students, completed a research project on fitting taper equations from standing trees using the whole-bole system (James and Kozak 1984). 
Dr. Demaerschalk's departure from the Faculty in 1988 and various administrative assignments to the other three members of the team in the 1980s reduced our taper research productivity significantly. However, Dr. R. Monty Newnhman's (who became a Research Scientist with the Canadian Forestry Service at Petawawa National Forestry Institute) work on "variable form" taper functions inspired me to initiate a new research project. Based on his basic idea, I developed a new approach with a continuous function describing the shape of the bole from ground to top by using a "changing exponent" to describe the neiloid, paraboloid, and conic forms of the stem (Kozak 1988). This equation is known in the literature as the "variable-exponent taper equation" and was adopted by the B.C. Ministry of Forests in 1989. To the best of my knowledge, this taper model or a slightly modified form of it is also used in Alberta, Saskatchewan, and several places in the United States, Europe, and Asia. The main advantage of this taper estimating system over the "segmented taper models" like the "whole-bole system" is that it is usually much easier to fit and it provides better estimations of diameter inside bark from ground to the top of the tree (Fig. 1, and also Kozak and Smith 1993).

After a few years of using the 1988 variable-exponent taper model, we realized that its merchantable volume estimation was not completely without bias for some B.C. species-mainly for large western hemlock (Tsuga heterophylla) and western redcedar trees (Thuja plicata). As a result, a modified version of the 1988 equation was developed in 1994 (Kozak 1997). This model estimated merchantable volume for most species without bias. However, some reviewers criticized it because its exponent contained several polynomial terms and other transformations of the same regressor variable (proportional height from ground), resulting in multicollinearity problems.

After completion of her Ph.D. in Biometrics, Dr. Valerie M. LeMay joined the Faculty in 1989 to teach forest measurements. Charles K. Muhairwe, one of her Ph.D. students, wrote his thesis on "dynamic taper models." He used the 1988 variable-exponent model to describe the stem profile of the growing trees (Muhairwe 1993). After completion of his Ph.D. program, he carried out another research program jointly with Dr. LeMay and me to study the effects of adding tree, stand, and site variables to the 1988 variable-exponent taper equation (Muhairwe et al. 1994). As a follow-up to this project, I initiated a study on the effects of upper stem measurements on the predictive ability of the 1988 variable-exponent taper equations (Kozak 1998). The general conclusion from both studies was that additional variables resulted in only marginal improvements to the published version of the 1988 taper function. Therefore, the cost of measuring additional variables was not justified. It should be noted that the 1988 taper model, in its original form, is still the official volume and taper estimation system in British Columbia.

Upon retirement from UBC, I set out to study two other forms of the variable-exponent taper equation. The impetus behind this research was simply to solve the volume estimation problem with the 1988 equation and the multicollinearity problem with the 1994 equation. These two equations are described and compared to the 1988 and 1994 models in the following sections.

\section{Methods}

\section{Description of two new variable-exponent equations}

Four models were compared to evaluate their predictive ability in this study. The first two, Equations 1 and 2, are the 1988 and the 1994 taper models. Equations 3 and 4 are new models developed and tested in 2001 and 2002, respectively. These four models will be referred to as the 88, 94, 01, and 02 models in this paper. The following symbols are common to all four models:

$D=$ outside bark diameter at breast height $(\mathrm{cm})$

$H=$ total tree height $(\mathrm{m})$

$h_{i}=$ height from ground $(\mathrm{m})$

$z_{i}=h_{i} / H$, proportional height from ground

$d_{i}=$ inside bark diameter at $h_{i}$ height from ground $(\mathrm{cm})$

$\hat{d}_{i}^{l}=$ predicted inside bark diameter at $h_{i}$ height from ground $(\mathrm{cm})$

The mathematical forms of the four models are:

Model 88:

$$
\hat{d}_{i}=a_{0} D^{a_{1}} a_{2}^{D} X_{i}^{b_{1} z_{i}^{2}+b_{2} \ln \left(z_{i}+0.001\right)+b_{3} z_{i}^{1 / 2}+b_{4} e^{z_{i}}+b_{5}(D / H)}
$$

where:

$$
\begin{aligned}
& X_{i}=\left[1.0-\left(h_{i} / H\right)^{1 / 2}\right] /\left[1.0-p^{1 / 2}\right] \\
& p=\text { proportional height of the "inflection point," } 0.1-0.3, \\
& \text { depending on the species }
\end{aligned}
$$

Model 94:

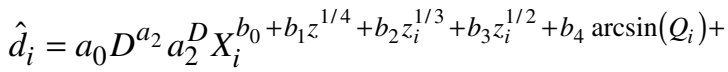

$$
\begin{aligned}
& b_{5}\left[1 /\left(D / H+z_{i}\right)\right]+b_{6} H
\end{aligned}
$$

where:

$$
\begin{aligned}
& X_{i}=\text { as above } \\
& Q_{i}=\left[1.0-\left(h_{i} / H\right)^{1 / 2}\right] \\
& p=0.01
\end{aligned}
$$

Model 01:

$$
\hat{d}_{i}=a_{0} D^{a_{1}} X_{i}^{b_{0}+b_{1}\left[1 / e^{D / H}\right]+b_{2} D^{X_{i}}+b_{3} X_{i}^{D / H}}
$$

where:

$$
\begin{aligned}
& X_{i}=\left[1.0-\left(h_{i} / H\right)^{1 / 4}\right] /\left[1.0-p^{1 / 4}\right] \\
& p=0.01
\end{aligned}
$$

Model 02:

$$
\begin{aligned}
\hat{d}_{i}= & a_{0} D^{a_{1}} H^{a_{2}} X_{i}^{b_{1} z_{i}^{4}+b_{2}\left[1 / e^{D / H}\right]+b_{3} X_{i}^{0.1}+} \\
& b_{4}[1 / D]+b_{5} H^{Q_{i}}+b_{6} X_{i}
\end{aligned}
$$

where:

$$
\begin{aligned}
& X_{i}=\left[1.0-\left(h_{i} / H\right)^{1 / 3}\right] /\left[1.0-p^{1 / 3}\right] \\
& Q_{i}=\left[1.0-\left(h_{i} / H\right)^{1 / 3}\right] \\
& p=1.3 / H
\end{aligned}
$$

If desired, the variable-exponent equation can easily be modified or improved on for local conditions and different species by changing one or more of: (i) the terms in the exponent; (ii) the base $\left(X_{i}\right)$ of the exponent; or (iii) the multiplier of the base (e.g., $a_{0} D^{a_{1}} H^{a_{2}}$ for model 02). These ideas were used to create models 94, 01, and 02 based on the original 88 model. The main advantage of the two new (01 and 02) models over the 88 and 94 models is that they have much lower multicollinearity. 


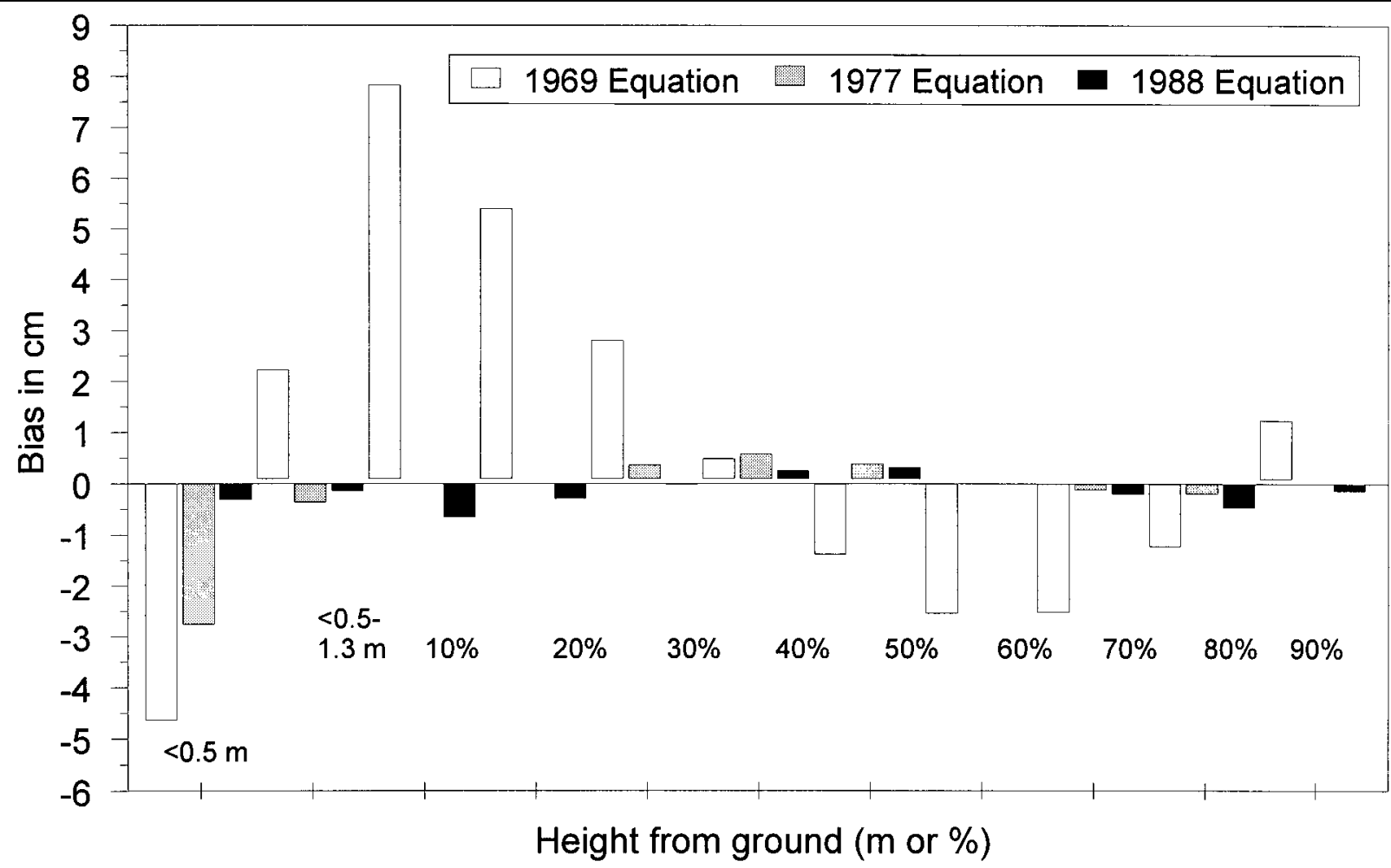

Fig. 1. Average biases of estimating inside bark diameters of 603 coastal Douglas-fir trees using the 1969, 1977 and 1988 equations.

1969 Equations: $\hat{d}_{i}=\sqrt{b_{0}+b_{1} z_{i}+b_{2} z_{i}^{2}}$

1977 Equation: $\hat{Y}_{i}=a_{0} z_{i}^{a_{1}} a_{2}^{\left(1-z_{i}\right)}$ from inflection point to top

$\hat{Y}_{i}=b_{0}+b_{1}\left(1-z_{i}\right)^{b_{2}}$ from ground to inflection point

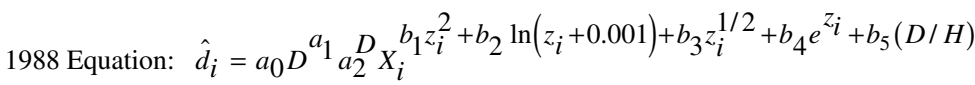

Where:

$D=$ outside bark diameter at breast height $(\mathrm{cm})$

$H=$ total tree height $(\mathrm{m})$

$h_{i}=$ height from ground $(\mathrm{m})$

$z_{i}=h / H$, proportional height from ground

$\hat{d}_{i}=$ predicted inside bark diameter at $h_{i}$ height from ground $(\mathrm{cm})$

$X_{i}=\left[1.0-\left(h_{i} / H\right)^{1 / 2}\right] /\left(1.0-p^{1 / 2}\right)$

$p=$ proportional height of the "inflection point", $0.1-0.3$, depending on the species

$a_{0}, a_{1}, a_{2}, b_{1} \ldots b_{5}=$ regression coefficient

$\hat{Y}_{i}=d_{i} / D I$, where $D I=$ diameter inside bark at the inflection point

Furthermore, model 01 is the simplest of the four models and 02 is believed to provide the "best prediction."

\section{Comparison of the four models}

The data used in this study were provided by the Resources Inventory Branch of the Ministry of Forests of British Columbia (presently: Vegetation Resources Inventory, Terrestrial Information Branch of Sustainable Resource Management) and consisted of over 100000 trees from 13 Biogeoclimatic Zones (Green and Klinka 1994) and 16 species. Of the several measurements recorded for each tree, the following were used in this study: diameter inside bark $\left(D I B\right.$ or $\left.d_{i}\right)$ at $0.30,0.46,0.61$, and $1.3 \mathrm{~m}$ above ground and at each $1 / 10$ of the height above breast height of the tree; total height of the tree $(H)$; diameter outside bark at breast height $(D B H$ or $D)$; individual log volumes for each measured section; and total stem volume. Some trees did not have all of the 14 possible $D I B$ measurements from the ground to the top of the tree. While data were available for more, 38 species groups (Table 2) contained enough trees (at least 300) to qualify for the study.

For all models, the parameters can either be estimated by a nonlinear least squares procedure or the models can be linearized by logarithmic transformation and estimated by linear least squares. In order to be consistent with previous publications (Kozak 1988, 1997), the latter procedure was used in this study. When the biases introduced by logarithmic transformations were greater 
than $1 \%$, Baskerville's (1972) correction was used. As recommended by Kozak and Smith (1993), both fit statistics and lack-of-fit statistics were used to compare and evaluate the four models. When a single statistic is used to evaluate a regression model (e.g., a coefficient of determination or the residual mean square), it is referred to as a "fit statistic" in this paper. When several values along the independent variable(s) or the predicted dependent variable are used (e.g., average volume biases by $D B H$ class or diameter inside bark biases by height class from ground to top) to evaluate a regression model, they are referred to as "lack-of-fit statistics" (see Kozak and Kozak 2003 for more detailed discussion).

The following fit statistics and lack-of-fit statistics were calculated for each species group and each model for three dependent variables of interest: diameter inside bark; total tree volume; and merchantable height.

1. Standard error of estimate (SEE):

$$
S E E=\sqrt{M S_{R E S}}
$$

where:

$$
\begin{gathered}
M S_{R E S}=\frac{S S_{R E S}}{n-m-1} \\
S S_{R E S}=\sum_{i=1}^{n}\left(y_{i}-\hat{y}_{i}\right)^{2}
\end{gathered}
$$

$n=$ number of observations;

$y_{i}=$ an observation of the dependent variable, which can be either diameter inside bark, volume, or merchantable height;

$\hat{y}_{i}=$ the predicted value of a given observation of the dependent variable;

$m=$ number of independent variables in the model;

$M S_{R E S}=$ residual mean squares; and

$S S_{R E S}=$ residual sum of squares.

2. Coefficient of determination $\left(R^{2}\right)$ :

$$
R^{2}=\frac{S S_{R E G}}{S S_{y}}=1-\frac{S S_{R E S}}{S S_{y}}
$$

where:

$S S_{R E G}=$ regression sum of squares;

$S S_{y}=$ corrected sum of squares of the dependent variable, calculated as:

$$
S S_{y}=\sum_{i=1}^{n}\left(y_{i}-\bar{y}\right)^{2}
$$

$\bar{y}=$ mean of the dependent variable;

3. Average absolute bias $(A B)$ :

$$
A B=\frac{\sum_{i=1}^{n}\left|y_{i}-\hat{y}_{i}\right|}{n}
$$

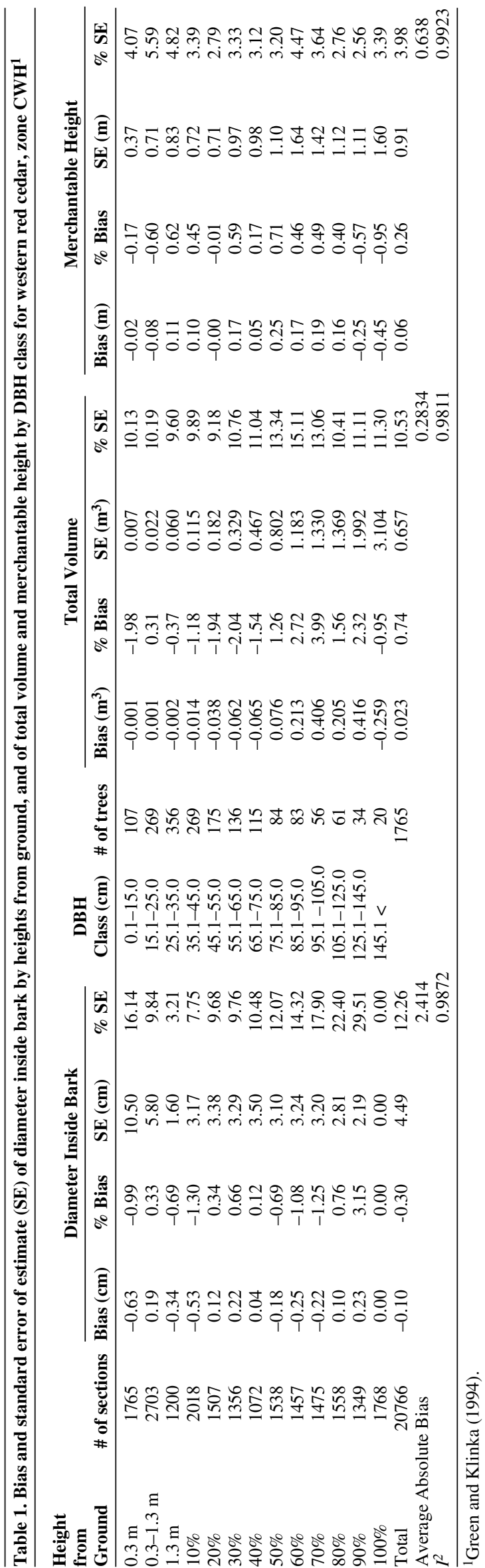


Table 2. Predictive ability indices by species and BEC zone for the four models studied. The ranks of the models are in parentheses

\begin{tabular}{|c|c|c|c|c|c|c|}
\hline $\begin{array}{l}\text { Species } \\
1\end{array}$ & BEC zone ${ }^{2}$ & No. of trees & 88 & 94 & 01 & 02 \\
\hline $\mathrm{AC}$ & BWBS & 585 & $3.00(4)$ & $2.11(2)$ & $2.22(3)$ & $1.94(1)$ \\
\hline $\mathrm{AT}$ & BWBS & 1784 & $2.58(3)$ & $2.64(4)$ & $1.58(1)$ & $2.47(2)$ \\
\hline $\mathrm{AT}$ & SBS & 843 & $3.17(4)$ & $2.00(2)$ & $2.28(3)$ & $1.72(1)$ \\
\hline B & BWBS & 310 & $2.44(4)$ & $2.17(2)$ & $2.14(1)$ & $2.42(3)$ \\
\hline B & CWH & 2325 & $2.83(4)$ & $2.03(1.5)$ & $2.03(1.5)$ & $2.50(3)$ \\
\hline B & ESSF & 2541 & $2.53(2.5)$ & $1.64(1)$ & $2.69(4)$ & $2.53(2.5)$ \\
\hline B & $\mathrm{ICH}$ & 1177 & $2.89(4)$ & $2.22(2)$ & $2.31(3)$ & $1.75(1)$ \\
\hline B & SBS & 3006 & $1.78(1)$ & $3.06(4)$ & $2.31(3)$ & $2.03(2)$ \\
\hline $\mathrm{C}$ & $\mathrm{CWH}$ & 1765 & $2.61(4)$ & $2.17(2)$ & $2.14(1)$ & $2.25(3)$ \\
\hline $\mathrm{C}$ & $\mathrm{ICH}$ & 3594 & $2.22(2.5)$ & $2.11(1)$ & $2.22(2.5)$ & $2.56(4)$ \\
\hline $\mathrm{D}$ & CWH & 663 & $2.67(3)$ & $2.94(4)$ & $2.39(2)$ & $1.39(1)$ \\
\hline $\mathrm{F}$ & CWH & 1114 & $2.47(4)$ & $1.83(1)$ & $2.39(2.5)$ & $2.39(2.5)$ \\
\hline $\mathrm{F}$ & $\mathrm{ICH}$ & 766 & $3.25(4)$ & $1.83(1)$ & $1.92(2)$ & $2.61(3)$ \\
\hline $\mathrm{F}$ & IDF & 1714 & $2.58(4)$ & $2.11(2)$ & $2.03(1)$ & $2.50(3)$ \\
\hline $\mathrm{F}$ & MS & 370 & $3.50(4)$ & $1.92(2)$ & $2.33(3)$ & $1.58(1)$ \\
\hline $\mathrm{F}$ & PP & 393 & $3.36(4)$ & $1.86(2)$ & $2.33(3)$ & $1.83(1)$ \\
\hline $\mathrm{F}$ & SBS & 520 & $3.08(4)$ & $1.97(2)$ & $2.28(3)$ & $1.78(1)$ \\
\hline $\mathrm{H}$ & CWH & 5716 & $2.47(3)$ & $2.58(4)$ & $2.44(2)$ & $2.00(1)$ \\
\hline $\mathrm{H}$ & ESSF & 552 & $2.11(1)$ & $2.22(2)$ & $2.81(4)$ & $2.25(3)$ \\
\hline $\mathrm{H}$ & $\mathrm{ICH}$ & 6076 & $2.44(2.5)$ & $2.67(4)$ & $2.44(2.5)$ & $1.94(1)$ \\
\hline $\mathrm{L}$ & $\mathrm{ICH}$ & 333 & $2.19(2)$ & $3.03(4)$ & $2.22(3)$ & $1.83(1)$ \\
\hline $\mathrm{L}$ & MS & 413 & $2.39(3)$ & $2.83(4)$ & $2.17(2)$ & $1.67(1)$ \\
\hline PL & BWBS & 1402 & $1.92(1.5)$ & $3.03(4)$ & $2.36(3)$ & $1.92(1.5)$ \\
\hline PL & ESSF & 647 & $2.25(2)$ & $3.06(4)$ & $2.42(3)$ & $1.67(1)$ \\
\hline PL & $\mathrm{ICH}$ & 455 & $2.69(3)$ & $2.81(4)$ & $2.00(2)$ & 1.61(1) \\
\hline PL & IDF & 870 & $2.19(2)$ & $3.14(4)$ & $2.56(3)$ & $1.44(1)$ \\
\hline PL & MS & 591 & $2.92(4)$ & $2.86(3)$ & $2.03(2)$ & $1.64(1)$ \\
\hline PL & SBS & 2047 & $1.94(1)$ & $2.67(4)$ & $2.64(3)$ & $2.19(2)$ \\
\hline PW & $\mathrm{ICH}$ & 312 & $1.89(1)$ & $2.00(2)$ & $2.61(4)$ & $2.44(3)$ \\
\hline PY & IDF & 318 & $3.00(4)$ & $1.75(1)$ & $2.50(3)$ & $2.14(2)$ \\
\hline S & BWBS & 2768 & $2.25(1.5)$ & $2.33(3)$ & $2.50(4)$ & $2.25(1.5)$ \\
\hline S & CWH & 858 & $2.31(2.5)$ & $1.81(1)$ & $2.86(4)$ & $2.31(2.5)$ \\
\hline S & ESSF & 1441 & $2.58(3)$ & $2.25(2)$ & $2.81(4)$ & $1.69(1)$ \\
\hline S & $\mathrm{ICH}$ & 1297 & $2.56(3)$ & $2.17(1)$ & $2.58(4)$ & $2.22(2)$ \\
\hline S & MS & 629 & $2.72(4)$ & $1.69(1)$ & $2.58(3)$ & $2.28(2)$ \\
\hline S & SBS & 2542 & $2.39(3)$ & $2.22(2)$ & $2.58(4)$ & $2.19(1)$ \\
\hline S & SWB & 382 & $1.89(1)$ & $2.47(3)$ & $2.61(4)$ & $2.31(2)$ \\
\hline Y & CWH & 484 & $2.64(3)$ & $2.31(2)$ & $2.94(4)$ & $1.56(1)$ \\
\hline Average & & 1410.6 & $2.55(4)$ & $2.33(2)$ & $2.38(3)$ & $2.05(1)$ \\
\hline
\end{tabular}

${ }^{1} \mathrm{AC}=$ aspen $; \mathrm{AT}=$ cottonwood $; \mathrm{B}=$ balsam $\mathrm{C}=$ red cedar; $\mathrm{D}=$ alder $\mathrm{F}=$ Douglas-fir $\mathrm{H}=$ western hemlock; $\mathrm{L}=$ larch; $\mathrm{PL}=$ lodgepole pine; $\mathrm{PW}=$ white pine; $\mathrm{PY}=$ yellow pine; $\mathrm{S}=$ spruce; and $\mathrm{Y}=$ yellow cedar.

${ }^{2}$ See Green and Klinka (1994) for definition of Biogeoclimatic Zones.

4. Average bias $(B)$ :

$$
B=\frac{\sum_{i=1}^{n}\left(y_{i}-\hat{y}_{i}\right)}{n}
$$

It should be noted that when the model is derived by the ordinary least squares (OLS) procedure, by definition, the average bias must be zero when computed for the entire data set. It is, therefore, not a suitable measure of fit in this case. Also, if the coefficient of determination is not calculated from residuals based on OLS estimates, it is usually symbolized by $I^{2}$ (correlation index squared) instead of $R^{2}$, and is referred to as the "estimated coefficient of determination."

To evaluate and compare the four taper models, all four of the above statistics were used as fit statistics, while only average biases and standard errors of estimate were used as lack-of-fit statistics. These lack-of-fit statistics were calculated by relative height class from ground to top for diameter inside bark estimation and by $D B H$ class for total tree volume and merchantable height estimation. ${ }^{2}$ Since a limited number of trees were present in some of the extreme $D B H$ classes for most species groups, the residual sum of squares terms in the standard errors of estimate for the $D B H$ classes and for all trees were calculated by dividing by $n$, instead of $n-m-1$, as given in eq. 5 .

\section{Results and Discussion}

By away of example, Table 1 indicates the fit statistics and lack-of-fit statistics calculated for western red cedar in the CWH zone, using model 01 . In the process of comparing the four models, 12 fit statistics and 6 lack-of-fit statistics were used to generate an average index for each model within each species group. The 12 fit statistics were standard error of estimate $(S E)$, estimated coefficient of determination $\left(I^{2}\right)$, average

\footnotetext{
${ }^{2}$ Since the number of trees for larger $\mathrm{DBH}$ classes was limited, unequal frequency class widths were used. For coastal species groups, $10-\mathrm{cm} D B H$ classes were used for trees below $95 \mathrm{~cm}$, and 20-cm $D B H$ classes were used for trees above $95 \mathrm{~cm}$. For the interior species groups, 5-cm $D B H$ classes were used for trees below $50 \mathrm{~cm}$, and 10-cm $D B H$ classes were used for trees above $50 \mathrm{~cm}$.
} 
bias $(B)$, and average absolute bias $(A B)$ calculated for each of the three dependent variables of inside bark diameter, total tree volume, and merchantable height. The six lack-of-fit statistics were the number of average biases exceeding plus or minus $3 \%$ $(>3)$, and general trend (TR) assessments for each of the three dependent variables.

Only two values were used for trend assessment. A value of 1 was assigned for no trend at all; that is, the positive and negative biases alternated in a random fashion (see Table 1) within $D B H$ or relative height classes. A value of 2 was assigned to show an obvious trend in average biases (for example, a consistent and substantial under or over estimation of the small and/or large trees in the cases of volume and merchantable height, or a consistent and substantial under or over estimation of inside bark diameter at the lower, middle, or the upper part of the stem). The four models were ranked from one to four (in the case of a tie, the average of the ranks for the tied models was assigned to each of the tied models) based on each one of the fit and lackof-fit statistics, with the exception of trend. ${ }^{3}$ The average of these 18 ranks for a given model was then calculated within each species group (Table 2). The average indices for the four models for all species groups are summarized in Table 3. The rank of each model for a given species group is shown in Table 2 in parentheses next to each index, and the frequencies of these ranks are summarized in Table 4.

In order to evaluate whether all of the 12 fit statistics and 6 lack-of-fit statistics are required for a fair assessment of the models' predictive ability, indices were created for various combinations of these 18 statistics. It is easy to see from the ranks in Table 3 that the overall average bias, compared to the other fit statistics, is not a consistent indicator of the goodness of the models, while the average biases by $D B H$ class and relative height class are important and reliable indicators of the trend of the predicted values (Table 1). The inconsistency of the overall average biases can easily be reasoned mathematically. First, this value is exactly zero for OLS models. Therefore, in this case, it is not useful for ranking various models. Second, for non-OLS models, as all these four models are, large positive and negative individual biases can easily average out to zero or close to zero, and again can be misleading in the ranking of the models. Based on these arguments, new indices were calculated without the overall average biases and their frequencies of ranks and model averages are given Table 5. While the ranking of the models for 38 species groups changed somewhat without the overall average bias, the models were ranked in the same way for 29 out of the 38 species groups.

To further evaluate if all the statistics, with the exception of overall biases, were needed to rank the four models for the 38 species groups, the average indices were calculated for all possible combinations of using one, two, three, or four of $A B, I^{2}$, $S E$, and $>3$ at a time (with trend included in each one of the combinations). Table 6 shows the number of times each of the four models ranked in exactly the same way as using all four statistics at a time. It can be seen that there is a $81.6 \%$ agreement using the best three statistics $\left(A B, I^{2}\right.$, and $\left.>3\right)$ at a time, $55.3 \%$ using the best two statistics ( $A B$ and $S E$, or $S E$ and $>3$ ), and $52.6 \%$ using the best single statistic $(S E)$.

${ }^{3}$ Since a value of one was assigned for no trend and two for some obvious trend, these values were used as ranks. 
Table 4. Frequency of indices and average indices by models based on all 12 fit statistics and six lack of fit statistics for all species groups

\begin{tabular}{|c|c|c|c|c|c|c|c|c|}
\hline \multirow[b]{2}{*}{ Model } & \multicolumn{7}{|c|}{ Rank } & \multirow{2}{*}{$\begin{array}{c}\text { Average } \\
\text { Index }\end{array}$} \\
\hline & 1.0 & 1.5 & 2.0 & 2.5 & 3.0 & 3.5 & 4.0 & \\
\hline 88 & 5 & 2 & 2 & 4 & 11 & 0 & 14 & 2.55 \\
\hline 94 & 8 & 1 & 14 & 0 & 3 & 0 & 12 & 2.33 \\
\hline 01 & 4 & 1 & 7 & 3 & 13 & 0 & 10 & 2.38 \\
\hline 02 & 18 & 2 & 7 & 3 & 6 & 0 & 2 & 2.05 \\
\hline
\end{tabular}

Table 5. Frequency of indices and average indices by models based on 9 fit statistics (all but allover average bias) and six lack of fit statistics for all species groups

\begin{tabular}{|c|c|c|c|c|c|c|c|c|}
\hline \multirow[b]{2}{*}{ Model } & \multicolumn{7}{|c|}{ Rank } & \multirow{2}{*}{$\begin{array}{c}\text { Average } \\
\text { Index }\end{array}$} \\
\hline & 1.0 & 1.5 & 2.0 & 2.5 & 3.0 & 3.5 & 4.0 & \\
\hline 88 & 6 & 0 & 5 & 0 & 9 & 2 & 16 & 2.54 \\
\hline 94 & 7 & 0 & 14 & 0 & 6 & 1 & 10 & 2.35 \\
\hline 01 & 5 & 0 & 8 & 0 & 17 & 0 & 8 & 2.31 \\
\hline 02 & 20 & 0 & 11 & 0 & 4 & 1 & 2 & 1.95 \\
\hline
\end{tabular}

The frequency of the ranks and the average ranks of the 38 species groups for each model using four statistics at a time are presented in Table 5, and Tables 7, 8, and 9 contain one example (the one considered "best") using three, two, and one statistics at a time, respectively. Comparing the frequencies of the ranks and the average ranks (Tables 5, 7, 8, and 9), it seems that the various combinations of the fit and lack-of-fit statistics groups rank the four models very similarly: 02 is consistently the best, 88 is the worst, while there is not much difference between 01 and 94 at second and third place. ${ }^{4}$ These results could be used to argue that it would be more economical or less time-consuming to use fewer statistics to evaluate several models. While this is seemingly true from Tables 5, 7, 8 , and 9 , the consistency of the ranking goes down significantly with the decreasing number of groups of statistics used (Table 6), especially when only two groups or one group are used.

Most taper equations are evaluated only by their predictive ability for diameter inside bark (Kozak and Smith 1993). Table 10 summarizes the indices, calculated from all 18 statistics, separately for diameter prediction, volume prediction, and merchantable height prediction, then for the combination of any two of the dependent variables, and lastly for the combination of all three dependent variables. The results for all three variables, of course, are the same as the averages in Table 2. These results indicate that the selection of the best model would be the same as the selection by all the dependent variables in all cases but one, while the selection of the best two models would only be the same in only one case. It is interesting to note that model 01 predicts merchantable heights better than any other model.

If average overall biases are ignored, it is unquestionable that model 02 ranks first for each of the fit and lack-of-fit statistics, with the exception of merchantable height estimation by average absolute bias, $I^{2}$, and standard error of estimate, and volume estimation by trend. In these four cases, however, model 02 ranks second (Table 3). Models 01 and 94 rank very closely behind at second or third in most ranking procedures in this

\footnotetext{
${ }^{4}$ It should be noted that the reason why the average indices are decreasing as less groups of statistics are used for ranking is that the expected value of the ranks from 1 to 4 is 2.5 , but the expected value of the ranks for trend is only 1.5 , and trend is included in every combination.
}

Table 6. Number and percent of agreements in ranking the 38 species groups using various fit and lack of fit statistics groups compared to all groups except average overall bias

\begin{tabular}{lcc}
\hline $\begin{array}{l}\text { Groups of } \\
\text { statistics used }\end{array}$ & $\begin{array}{c}\text { No. of agreements } \\
\text { out of 38}\end{array}$ & Percent agreements \\
\hline$I^{2}, S E,>3$ & 30 & 78.9 \\
$\mathrm{AB}, \mathrm{SE},>3$ & 30 & 78.9 \\
$A B, I^{2},>3$ & 31 & 81.6 \\
$A B, I^{2}, S E$ & 21 & 55.3 \\
$A B, I^{2}$ & 18 & 47.4 \\
$\mathrm{AB}, \mathrm{SE}$ & 21 & 55.3 \\
$\mathrm{AB},>3$ & 20 & 52.6 \\
$I^{2}, S E$ & 17 & 44.7 \\
$I^{2},>3$ & 17 & 44.7 \\
$\mathrm{SE},>3$ & 21 & 55.3 \\
$\mathrm{AB}$ & 17 & 44.7 \\
$I^{2}$ & 18 & 47.4 \\
$\mathrm{SE}$ & 20 & 52.6 \\
$>3$ & 9 & 23.7 \\
\hline
\end{tabular}

study, while the 88 model consistently ranks lowest. This ranking is also supported by the consistencies of the regression equations for the 38 species groups. Table 11 summarizes the number of equations for which some of the regression coefficients had different signs and a number of terms were eliminated from the model, because they were not significant at the 0.05 probability level. These results verify that the most stable, and therefore the most consistent, taper model out of the four studied here is model 02 , as only two out of the 38 equations had a regression coefficient with different sign, and only eight out of the 38 equations were reduced by a single nonsignificant term $(\alpha=0.05)$. It should be noted that six of these eight were $H^{a_{2}}$, while the other two were $I / D$ and $H^{Q}$.

\section{Conclusions}

It is unique in the literature that a study comparing taper models is based on 38 species groups consisting of 53603 measured trees. It can be concluded from this rather extensive study that several fit statistics and lack-of-fit statistics should be used to create indices for ranking taper models for practical applications. Also, the fit statistics and lack-of-fit statistics should be calculated for as many dependent variables (e.g., diameter inside bark, total or merchantable volume, and merchantable height) 
Table 7. Frequency of indices and average indices by models based on absolute average bias, estimated coefficient of determination, number of biases exceeding $3 \%\left(A B, I^{2},>3\right)$, and trend for all species groups

\begin{tabular}{|c|c|c|c|c|c|c|c|c|}
\hline \multirow[b]{2}{*}{ Model } & \multicolumn{7}{|c|}{ Rank } & \multirow{2}{*}{$\begin{array}{c}\text { Average } \\
\text { Index }\end{array}$} \\
\hline & 1.0 & 1.5 & 2.0 & 2.5 & 3.0 & 3.5 & 4.0 & \\
\hline 88 & 6 & 0 & 4 & 2 & 6 & 0 & 20 & 2.46 \\
\hline 94 & 7 & 1 & 14 & 0 & 5 & 0 & 11 & 2.30 \\
\hline 01 & 4 & 2 & 5 & 3 & 17 & 0 & 7 & 2.26 \\
\hline 02 & 19 & 1 & 10 & 1 & 7 & 0 & 0 & 1.92 \\
\hline
\end{tabular}

Table 8. Frequency of indices and average indices by models based on absolute average bias, standard error of estimate (AB, $S E)$, and trend for all species groups

\begin{tabular}{|c|c|c|c|c|c|c|c|c|}
\hline \multirow[b]{2}{*}{ Model } & \multicolumn{7}{|c|}{ Rank } & \multirow{2}{*}{$\begin{array}{c}\text { Average } \\
\text { Index }\end{array}$} \\
\hline & 1.0 & 1.5 & 2.0 & 2.5 & 3.0 & 3.5 & 4.0 & \\
\hline 88 & 7 & 0 & 10 & 1 & 11 & 0 & 9 & 2.39 \\
\hline 94 & 7 & 0 & 11 & 0 & 4 & 0 & 16 & 2.19 \\
\hline 01 & 6 & 0 & 5 & 2 & 16 & 0 & 9 & 2.10 \\
\hline 02 & 18 & 0 & 10 & 1 & 5 & 0 & 4 & 1.85 \\
\hline
\end{tabular}

Table 9. Frequency of indices and average indices by models based on standard error of estimate $(S E)$ and trend for all species groups

\begin{tabular}{|c|c|c|c|c|c|c|c|c|}
\hline \multirow[b]{2}{*}{ Model } & \multicolumn{7}{|c|}{ Rank } & \multirow{2}{*}{$\begin{array}{l}\text { Average } \\
\text { Index }\end{array}$} \\
\hline & 1.0 & 1.5 & 2.0 & 2.5 & 3.0 & 3.5 & 4.0 & \\
\hline 88 & 3 & 2 & 6 & 3 & 6 & 3 & 15 & 2.17 \\
\hline 94 & 9 & 7 & 3 & 3 & 3 & 2 & 11 & 2.02 \\
\hline 01 & 1 & 3 & 8 & 7 & 12 & 2 & 5 & 1.96 \\
\hline 02 & 16 & 4 & 5 & 5 & 5 & 1 & 2 & 1.75 \\
\hline
\end{tabular}

Table 10. Average predictive ability indices by model and the dependent variables: diameter inside bark (D), total tree volume (V), and merchantable height $(\mathbf{H})$ for all species groups

\begin{tabular}{lcccccc}
\hline Model & D & V & H & D\&V & D\&H & D\&V\&H \\
\hline 88 & $2.22(2)$ & $2.51(4)$ & $2.91(4)$ & $2.37(3)$ & $2.57(4)$ & $2.71(4)$ \\
94 & $2.33(3)$ & $2.20(2)$ & $2.45(3)$ & $2.27(2)$ & $2.39(3)$ & $2.33(3)$ \\
01 & $2.74(4)$ & $2.48(3)$ & $1.85(1)$ & $2.61(4)$ & $2.30(2)$ & $2.17(2)$ \\
02 & $1.92(1)$ & $2.09(1)$ & $2.10(2)$ & $2.03(1)$ & $2.03(1)$ & $2.10(1)$ \\
\hline
\end{tabular}

Table 11. Number of equations out of the 38 with coefficients of different signs and with non-significant terms

\begin{tabular}{lccccc}
\hline & \multicolumn{3}{c}{ Number of Equations } \\
\cline { 2 - 6 } Model & $\begin{array}{c}\text { With } \\
\text { coefficients of } \\
\text { different signs }\end{array}$ & $\begin{array}{c}\text { With at } \\
\text { least one }\end{array}$ & \multicolumn{3}{c}{$\begin{array}{c}\text { No. of variables } \\
\text { dropped }\end{array}$} \\
\cline { 3 - 7 } & 5 & 15 & 10 & $\mathbf{2}$ & $\mathbf{3}$ \\
\hline 88 & 15 & 17 & 11 & 4 & 2 \\
94 & 22 & 6 & 6 & & \\
01 & 2 & 8 & 8 & & \\
02 & 2 & & &
\end{tabular}

${ }^{*} \alpha=0.05$ level of significance used.

as the model will be used for. It is essential to use both fit and lack-of-fit statistics to create these indices in the process of comparing several taper models (Kozak and Smith 1993).

Kozak's 1988 variable-exponent taper equation can be successfully modified to obtain models with better predictive ability. Models 94, 01, and 02 are good examples of these modifications. This study demonstrated that model 02 was consistently the best taper model out of the four investigated for estimating diameter inside bark, tree or log volumes, and merchantable height, and model 01 was the simplest in form and the best for estimating merchantable height.

\section{Acknowledgments}

Data were provided by the Resources Inventory Branch, Ministry of Forests of British Columbia. The author wishes to thank
Drs. R.A. Kozak, V.M. LeMay and P.L. Marshall for their reviews and valuable recommendations.

\section{References}

Baskerville, G.L. 1972. Use of logarithmic regression in estimation of plant biomass. Can. J. For. Res. 2: 49-53.

Demaerschalk, J.P. 1971. An integrated system for the estimation of tree taper and volume. M.F. Thesis. Fac. For., Univ. BC, Vancouver B.C.

Demaerschalk, J.P. 1973. Derivation and analysis of compatible tree taper and volume estimating systems. Ph.D. Thesis. Fac. For., Univ. BC, Vancouver B.C.

Demaerschalk, J.P. and A. Kozak. 1977. The whole-bole system: a conditioned dual-equation system for precise prediction of tree profiles. Can. J. For. Res. 7: 488-497.

Green, R.N. and K. Klinka. 1994. Field guide to the identification and interpretation of ecosystems in the Vancouver Forest Region, B.C. Ministry of Forests, Victoria. For. Land. Manage. Handb. 28.

Fries, J. and B. Marten, B. 1965. On the use of multivariate methods for the construction of tree taper curves. Advisory Group of Forest Statisticians of the IUFRO Section 25. Paper No. 9, Stockholm Conference, October 1965.

James, C.A. and A. Kozak. 1984. Fitting taper equations from standing trees. For. Chron. 60: 157-161.

Kozak, A. 1988. A variable-exponent taper equation. Can. J. For. Res. 18: 1363-1368.

Kozak, A. 1997. Effects of multicollinearity and autocorrelation on the variable-exponent taper functions. Can. J. For. Res. 27: 619-629. 
Kozak, A. 1998. Effects of upper stem measurements on the predictive ability of a variable-exponent taper equation. Can. J. For. Res. 28: 1078-1083.

Kozak, A. and R. Kozak. 2003. Does cross validation provide additional information in the evaluation of regression models? Can. J. For. Res. 33: 976-987.

Kozak, A., D.D. Munro and J.H.G. Smith. 1969. Taper functions and their application in forest inventory. For. Chron. 45: 278-283. Kozak, A. and J.H.G. Smith. 1966. Critical analysis of multivariate techniques for estimating tree taper suggests that simpler methods are best. For. Chron. 42: 458-463.

Kozak, A. and J.H.G. Smith. 1993. Standards for evaluating taper estimating systems. For. Chron. 69: 438-444.
Muhairwe, C.K. 1993. Examination and modeling of tree form and taper over time for interior lodgepole pine. Ph.D. Thesis. Fac. For., Univ. BC, Vancouver B.C.

Muhairwe, C.K., V.M. LeMay and A. Kozak. 1994. Effects of adding tree, stand, and site variables to Kozak's variable-exponent taper equation. Can. J. For. Res. 24: 252-259.

Newnham, R.M. 1958. A study of form and taper of stems of Douglas-fir, western hemlock, and western red cedar on the UBC Forest. M.F. Thesis. Fac. For., Univ. BC, Vancouver B.C. 